\title{
Blackfriars
}

Middle Ages. It is no clearer in our own time than it was five hundred years ago what useful service is rendered by living on interest without working for a livelihood.

Joseph Clayton.

SIR,

\section{THE WESTMINSTER STATIONS.}

After reading Mr. Eric Gill's Apologia in the August BLACKFrIARS it occurs to me that the effect he desired and strove to obtain might be gained much more easily-since everyone now knows how to read-by merely writing the names of the Stations underneath each wooden cross, leaving the subject wholly to the imagination and devotion of the individual! Personally I should prefer this-at Westminster Cathedral. The idea could also be carried out for Rosary Chapels and in fact everywhere where pictorial representation has hitherto been the accepted rule. Slabs instead of statues, lettered glass in place of figured; why not?

Yours faithfully,

N. Shelley.

SIR,

MR. ERIC GILL'S REPLY.

In reply to your cor respondent, $\mathrm{N}$. Shelley, when I said that my carvings at Westminster Cathedral were "what in words is called plain language and in music plain chant " 1 committed an indiscretion. I complimented myself unduly. Nevertheless, your correspondent misunderstands the difficulty of the situation for, much as he (or she) and 1 would prefer plain lettered tablets to the usual pictorial banalities, the human appetite foi pictures, statues and ornaments is not to be denied, and our business, therefore, is to discover how that appetite (divinely implanted, be it remembered) can be justly satisfied.

It is not justly satisfied by church-furnishing companies nor by architects and contractors. It can only be justly satisfied by a return to the employment of responsible workmen and artists. In former times, before the modern 